\title{
Professional soccer player with an in-game ankle injury
}

\section{A. Iqbal ${ }^{1}$ (D) - E. McLoughlin ${ }^{1} \cdot$ R. Botchu ${ }^{1} \cdot$ S. L. James ${ }^{1}$}

Published online: 16 June 2019

(C) ISS 2019

A professional soccer player sustains an ankle inversion injury and is unable to continue playing (Fig. 1).
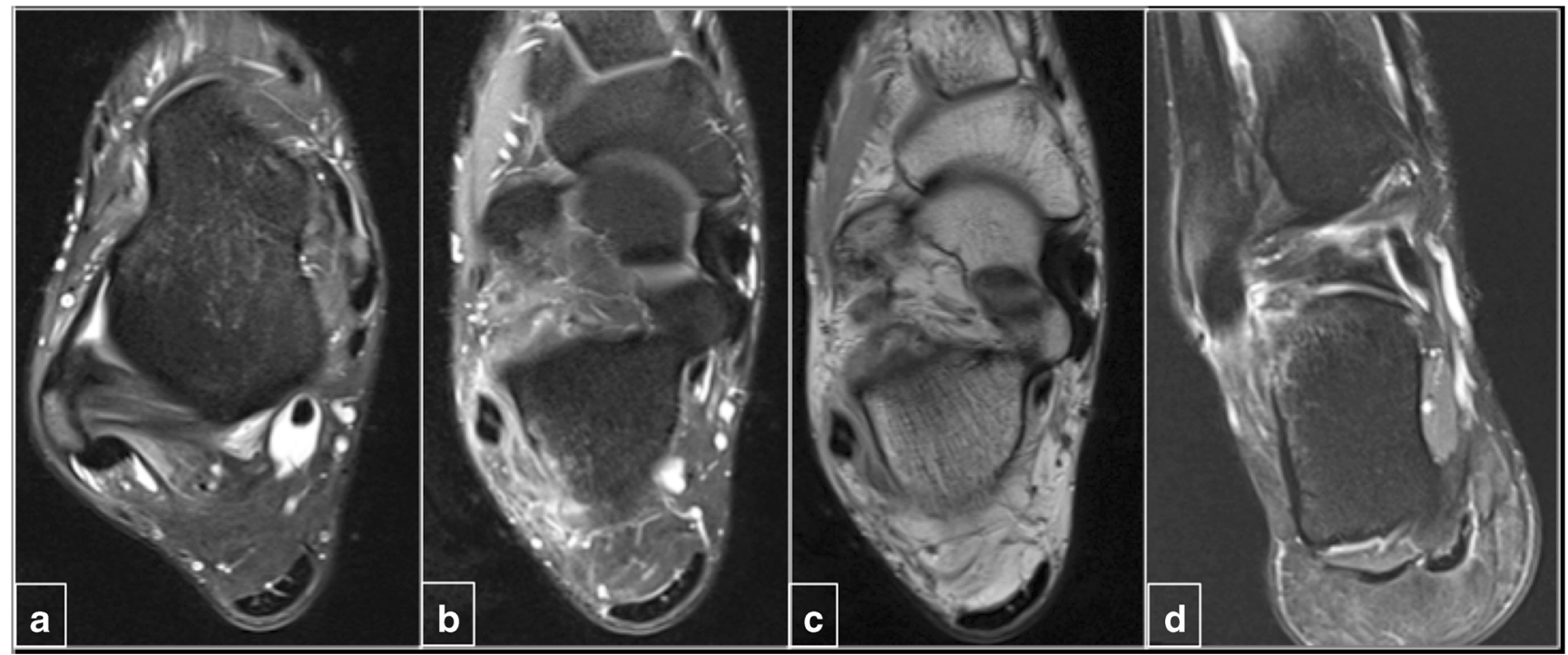

Fig. 1 PDFS Axial (a, b), PD axial (c), PDFS coronal (d) of the ankle

\section{Compliance with ethical standards}

Publisher's note Springer Nature remains neutral with regard to jurisdictional claims in published maps and institutional affiliations.

Conflict of interest No conflicts of interest.

The diagnosis can be found at https://doi.org/10.1007/s00256-01903254-5

A. Iqbal ai5720@doctors.net.uk

1 Department of Musculoskeletal Radiology, Royal Orthopaedic Hospital NHS Foundation Trust, Bristol Road South Northfield, Birmingham, UK 